\title{
Analisa Desain dan Perancangan Ruang Vakum Medium Sebagai Media Pembangkitan Plasma Oksigen Menggunakan Gelombang Mikro 2,45 GHZ
}

\author{
Antonius Prisma Jalu Permana \\ Universitas Katolik Widya Karya Malang \\ antonius.prisma@widyakarya.ac.id \\ Danang Murdiyanto \\ Universitas Katolik Widya Karya Malang \\ danang_t.mesin@widyakarya.ac.id \\ Bernardus Crisanto Putra Mbulu \\ Universitas Katolik Widya Karya Malang \\ chris_bernardo666@widyakarya.ac.id
}

\begin{abstract}
In line with the development of thin film technology, its also developing plasma-based removal techniques such as plasma ashing. Plasma is an ionized gas-like phase. Ionized gas when the temperature approaches or exceeds atomic ionization energy. The atoms are the ionized into positive and negative ions. The purpose of this research to analyze the working system of plasma generation using $2,45 \mathrm{GHz}$ microwaves. The plasma reactor was successfully operate, but it only maintain to generate plasma in short time. The reactor broke because it couldn't hold the bombardment energy of particles which the energy was $1,623 \times 10^{-24}$ for each every second. At last, the reactor could maintain the plasma only for $\pm 240 \mathrm{~s}$.
\end{abstract}

Keywords: microwave, plasma, ashing, vacuum, mean free path, ionization.

\begin{abstract}
Abstrak
Sejalan dengan perkembangan teknologi lapisan tipis, berkembang pula teknik penghapusan lapisan tersebut berbasis plasma yaitu plasma ashing. Plasma merupakan fasa mirip gas yang terionisasi. Gas terionisasi pada saat temperaturnya mendekati atau melebihi energi ionisasi atom. Atom - atom tersebut kemudian terionisasi menjadi ion positif dan ion negatif. Tujuan dari penelitian ini adalah untuk menganalisa sistem kerja dari pembangkitan plasma menggunakan gelombang mikro 2,45 GHz. Reaktor yang terbentuk berhasil digunakan dalam proses pembangkitan plasma, namun belum dapat mempertahankan plasma dalam waktu lama. Pecahnya reaktor diakibatkan karena tidak mampunya reaktor menahan energi dari partikel sebesar $1,623 \times 10^{-24} \mathrm{~J}$ per partikel per detik. Sehingga reaktor hanya dapat mempertahankan plasma selama $\pm 240 \mathrm{~s}$.
\end{abstract}

Kata kunci: gelombang mikro, plasma, ashing, vakum, mean free path, ionisasi

\section{PENDAHULUAN}

Secara fisis, material dibagi menjadi empat fasa, yaitu padat, cair, gas, dan plasma. Plasma merupakan fasa mirip gas yang terionisasi. Gas terionisasi pada saat temperaturnya mendekati atau melebihi energi ionisasi atom. Atom - atom tersebut kemudian terionisasi menjadi ion positif dan ion negatif. Partikel - partikel bermuatan tersebut tidak bisa dinyatakan bergerak bebas, karena terpengaruh oleh medan listrik sesamanya. 
Jurnal PRAXIS | Vol. 2 | No. 2 | Maret 2020

Pada perkembangannya, plasma menjadi suatu teknologi tinggi yang penting dalam proses produksi terutama dibidang teknologi lapisan tipis. Lapisan tipis merupakan suatu teknologi dimana merupakan modifikasi permukaan dengan melapiskan suatu lapisan tipis. Hal ini menjadi efisien dikarenakan dapat mengubah properti suatu material dari produk hanya dengan melapiskan lapisan tersebut. Sejalan dengan perkembangan teknologi lapisan tipis, berkembang pula teknik penghapusan lapisan tersebut berbasis plasma yaitu plasma ashing.

Teknik plasma ashing merupakan teknik penghapusan suatu lapisan tipis dari produk. Tujuan dari penghapusan ini adalah untuk melapiskan ulang lapisan yang telah rusak / aus sehingga lapisan menjadi baik lagi dan dapat digunakan kembali. Penelitian sebelumnya oleh Tatsuhiko Aizawa dilakukan proses ashing lapisan DLC pada milling-tool. Permukaan milling-tool tersebut akan dilapisi ulang dengan DLC, sehingga lapisan DLC sebelumnya harus dibersihkan terlebih dahulu dengan teknik plasma ashing. Proses plasma ashing dilakukan pada parameter frekuensi $2 \mathrm{MHz}$, densitas elektron $10^{17} \mathrm{~m}^{-3}$, densitas ion $5 \mathrm{x}$ $10^{16} \mathrm{~m}^{-3}$, dan menggunakan gas oksigen. Hasilnya, lapisan DLC pada milling-tool setebal $3 \mu \mathrm{m}$ bersih pada proses selama 7200 s (Aizawa, Masaki, \& Sugita, 2014).

Dalam penelitian ini dilakukan pembangkitan plasma menggunakan gelombang mikro 2,45 GHz. Penelitian ini melanjutkan penelitian sebelumnya oleh Antonius Prisma (P \& Mbulu, 2018) yang mana reaktor plasma yang berhasil dibangun mengalami permasalahan di mana ketika plasma diaktifkan dalam waktu lama maka reaktor pecah. Sehingga pada penelitian ini reaktor akan di desain ulang dengan menggunakan metal.

\section{LANDASAN TEORI}

Plasma merupakan suatu fasa mirip gas yang terionisasi dimana gas akan terioniasasi saat temperaturnya mendekati atau melebihi energi ionisasi atom. Atom atom tersebut kemudian terionisasi menjadi ion positif dan ion negatif. Partikel - partikel bermuatan tersebut tidak bisa dinyatakan bergerak bebas, karena terpengaruh oleh medan listrik sesamanya. Ada tiga parameter mendasar dari plasma, yaitu densitas partikel n (diukur dalam partikel setiap meter kubik), temperature $\mathrm{T}$ untuk masing - masing spesies (biasa diukur dalam $\mathrm{eV}$, dimana 1 $\mathrm{eV}=11605 \mathrm{~K}$ ), dan medan magnet steadystate (Bellan, 2006). Plasma tidak hanya terdiri dari partikel bermuatan saja, ada juga 
Jurnal PRAXIS | Vol. 2 | No. 2 | Maret 2020

partikel yang netral, dan jumlahnya juga mempengaruhi sistem tersebut.

Plasma terbentuk dari ionisasi gas yang stabil dengan jumlah dari ion positif dan negatif yang sama. Ion - ion yang bebas tersebut memiliki muatan, namun dalam jarak pendek, sehingga ion tersebut tidak mengalami interaksi elektromagnet kecuali ion tersebut bertabrakan. Hal ini menjadi salah satu properti elektrik dari plasma. Adanya atom - atom yang terionisasi mengakibatkan plasma bersifat konduktor dimana bereaksi kuat dengan suatu medan elektromagnetik. Sama halnya dengan gas, plasma tidak memiliki bentuk dan volume yang tetap.

Plasma dibangkitkan dengan cara memberikan energi pada suatu gas netral yang mengakibatkan gas menjadi bermuatan. Elektron dan ion terbentuk ketika elektron atau foton dengan energi yang cukup menabrak / bertabrakan dengan atom netral dan molekul pada gas tersebut. Salah satu cara sumber energi untuk membangkitkan plasma adalah energi thermal, di mana reaksi kimia eksothermik pada molekul digunakan sebagai sumber energi utama. Kompresi gas secara adiabatik juga mampu memanaskan gas ke titik terbentuknya plasma (Conrads \& Schmidt, 2000).
Dalam prosesnya dibutuhkan suatu wadah atau reaktor yang dapat menjaga agar keadaan gas berada dalam keadaan vakum. Pada reaktor terdapat dua buah elektroda yang akan menjadi titik pertemuan antara aliran listrik dan aliran gas. Kedua elektroda ini berfungsi menjadi anoda dan katoda. Ketika medan listrik mengaliri kedua buah elektroda dan di saat yang bersamaan ketika gas sudah dialirkan, maka akan terjadi beda potensial yang tinggi antara keduanya. Akibatnya energi thermal dari gas meningkat sehingga menimbulkan pelepasan elektron dari orbit atomnya. Energi yang dihasilkan di dalam plasma dapat berupa panas dan tekanan sehingga diperlukan wadah yang tahan terhadap panas dan tekanan tersebut. Jika arus listrik yang digunakan cukup besar dan memiliki lebar pulsa yang pendek, maka tekanan yang dihasilkan cukup besar.

Pada plasma, terdapat tiga proses yang terjadi dalam reaktor. Proses tersebut adalah ionisasi, eksitasi, dan dissosiasi:

\section{Ionisasi}

Plasma terbentuk pada ruang vakum dengan aliran gas konstan pada tekanan rendah sekitar 1 mbar. Gas ini dikenakan radio frequency (RF) dimana potensial mengakibatkan ionisasi parsial gas. Dalam proses ionisasi, elektron yang 
Jurnal PRAXIS | Vol. 2 | No. 2 | Maret 2020

terikat dalam sebuah atom akan terlepas dari atom tersebut.

2. Eksitasi

Proses transfer energi dimana memungkinkan elektron pada atom untuk naik ke level energi yang lebih tinggi.

\section{Dissosiasi}

Proses lain yang dapat terjadi adalah dissosiasi molekul. Dissosiasi terjadi jika elektron menabrak suatu molekul maka molekul tersebut akan terpisah menjadi atom - atom (Grigoryev \& Gorobchuk, 2014).

$$
\begin{aligned}
& \mathrm{CF}_{4}+\mathrm{e} \rightarrow \mathrm{CF}_{3}+\mathrm{F}+\mathrm{e} \\
& \mathrm{CF}_{4}+\mathrm{e} \rightarrow \mathrm{CF}_{2}+2 \mathrm{~F}+\mathrm{e}
\end{aligned}
$$

$\begin{array}{rrr}\text { Hasil } & \text { normal } & \text { dissosiasi } \\ \text { merupakan } & \text { peningkatan } & \text { reaktivitas }\end{array}$
kimia, dikarenakan hasil dissosiasi biasanya lebih reaktif daripada bentuk asal. Dissosiasi bisa diikuti dan tidak diikuti oleh proses ionisasi , misalnya:

$$
\mathrm{e}+\mathrm{CF}_{4} \rightarrow 2 \mathrm{e}+\mathrm{CF}_{3}{ }^{+}+\mathrm{F}
$$

(Dissosiasi Ionisasi)

Pada plasma, terdapat berbagai macam spesies akibat dari proses ionisas, eksitasi, dissosiasi, dan kombinasi dari ketiganya. Masing - masing spesies mengalami tabrakan yang kompleks antara satu dengan lainnya. Mempertimbangkan elektron menumbuk ion diam secara langsung. Karena ukuran ion besar, hampir tidak terjadi perubahan pada ion dan elektron akan terpantulkan kembali dengan kecepatan yang hampir sama. Pada saat terjadi tumbukan, akan terjadi pertukaran energi berdasar pada Hukum Kekekalan Energi, yaitu:

$$
\mathrm{m}_{1} \cdot \mathrm{v}_{1}=\mathrm{m}_{2} \cdot \mathrm{v}_{2}
$$

Tetapi pada tumbukan di plasma, hal ini tidak terjadi. Pada kasus tumbukan antara ion dan elektron yang terjadi adalah

$$
\frac{m m_{i} v_{i}}{2}=\frac{4\left(m_{\epsilon} / m_{i}\right) m_{\epsilon} v_{\epsilon}^{2}}{2}
$$

Demikian, elektron harus membuat $\approx m_{w} / m_{r}$ seperti itu agar energi dapat ditransfer sepenuhnya. Karenanya, $v_{E \theta t}=\left(m_{e} / m_{t}\right) / v_{e q}$ (Bellan, 2006).

Demikian pula, jika ion menumbuk elektron maka elektron akan terlempar hingga dua kali kecepatan awal ion (dengan anggapan terjadi pada titik pusat massa). Elektron mendapatkan energi $m_{q} v_{t}^{2} / 2$ sehingga, $\sim m_{i} / m_{e}$ dibutukan agar pada tumbukan terjadi transfer energi total ke elektron. Lain halnya jika terjadi tumbukan pada partikel dengan netral. Jika partikel menumbuk netral, maka dengan mudah akan menyebar tanpa adanya pertukaran energy internal dari netral, kejadian ini disebut elastic scattering. Tumbukan tersebut juga bisa terjadi ransfer energi ke struktur netral dan menyebabkan perubahan energi internal pada netral, kejadian ini disebut inelastic scattering. Inelastic scattering meliputi 
Jurnal PRAXIS | Vol. 2 | No. 2 | Maret 2020

ionisasi dan eksitasi pada level transisi atomik (diikuti dengan radiasi optis).

Proses lain dapat terjadi ketika ion menumbuk netral. Ion dapat menangkap elektron dari netral sehingga terjadi netralisasi ketika diikutin ionisasi dari netral. Kejadian ini disebut charge exchange, hal ini digunakan untuk memproduksi energetic neutral beams. Karena ion memiliki massa yang tidak jauh berbeda dengan netral, ion dapat dengan cepat bertukar energi dengan netral dan cenderung teradi kesetimbangan thermal dengan netral jika terionisasi lemah pada plasma (Bellan, 2006).

Vakum merupakan keadaan di mana udara atau gas apapun dihilangkan atau dikeluarkan, meskipun pada kenyataan vakum total tidak bisa dicapai. Banyaknya gas yang dibuang bergantung pada tujuannya. Pada tekanan atmosfer, molekul udara secara konstan membombardir permukaan. Molekul tersebut dapat memantulkan diri terhadap permukaan, bisa menempel pada permukaan, atau bisa terjadi reaksi kimia dengan permukaan.

Kecepatan pompa merupakan laju volumetrik dimana gas dialirkan melewati bidang. Secara metematis dituliskan sebagai daya hisap pompa dibagi dengan tekanannya.

$$
S=\frac{Q}{P}
$$

$$
\begin{aligned}
& \mathrm{P}=\operatorname{tekanan}(\mathrm{Pa}) \\
& \mathrm{S}=\operatorname{kecepatan} \text { pompa }\left(\mathrm{m}^{3} / \mathrm{s}\right)
\end{aligned}
$$

Daya hisap merupakan kemampuan pompa mengeluarkan gas (jumlah gas pada tekanan yang diketahui) per satuan waktu (O’Hanlon, 2003).

$$
Q=\frac{d}{d t}(P V)
$$

Laju alir gas dapat dituliskan dengan dua cara, yang pertama dituliskan dalam unit dari daya hisap seperti Pa-m³/s atau Torr-L/s dan yang kedua dituliskan dalam konversi kuantitas kg-moles/s atau kg/s. Dalam SI, daya hisap digunakan satuan $\mathrm{Pa}-\mathrm{m}^{3} / \mathrm{s}$, sejenis dengan dimensi daya dimana $1 \mathrm{~Pa}-\mathrm{m}^{3} / \mathrm{s}=1$ $\mathrm{J} / \mathrm{s}=1 \mathrm{~W}$.

\section{Gambar 1.}

Daya Hisap Pompa yang Dibutuhkan dan Rentang Instrument. (O’Hanlon, 2003)

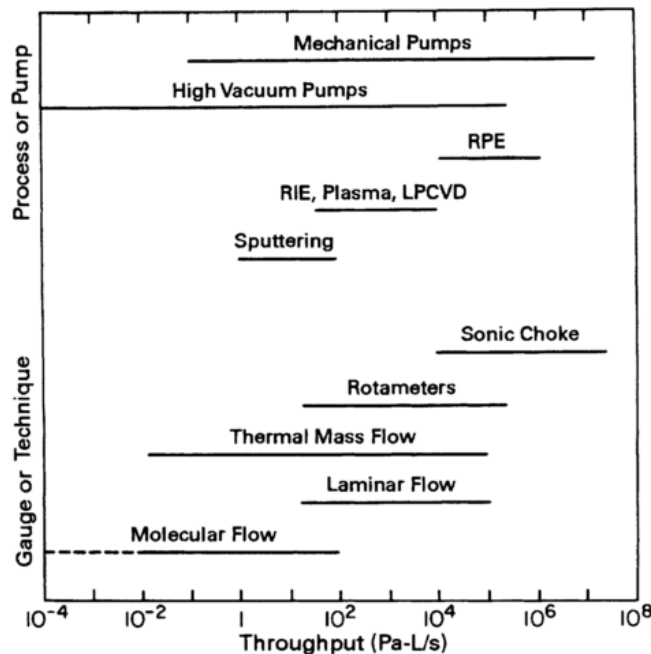

Laju alir molar N' memiliki satuan SI kg-mol/s dan merepresentasikan banyaknya kg-mol gas yang mengalir per detiknya. Laju dimana: $\mathrm{Q}=$ daya hisap pompa $\left(\mathrm{Pa}-\mathrm{m}^{3} / \mathrm{s}\right)$ 
Jurnal PRAXIS | Vol. 2 | No. 2 | Maret 2020

alir molar dan daya hisap saling berhubungan dari hukum gas ideal.

terendah yang dapat dicapai dari bejana vakum (Umrath, 1998).

$P V=N k T=\frac{N}{N_{n}}\left(N_{0} k j T=N^{\prime} R T\right.$

dimana N' kuantitas molar (kg-mol) dari gas, $\mathrm{R}=\mathrm{N}_{0} \mathrm{k}=8314 \mathrm{~kJ} /(\mathrm{K}-\mathrm{kg}$ mol). Laju alir molar pada temperatur konstan didapatkan dari turunan terhadap waktu dari persamaan (2.8) (O’Hanlon, 2003).

$$
\begin{gathered}
\frac{d}{d t}(P V)=Q=E T \frac{d N^{t}}{d t} \\
\frac{d N^{t}}{d t}(\mathrm{~kg}-\mathrm{mol} / \mathrm{s})=\frac{Q}{R T}=1.21 \times 10^{-4}\left(\frac{Q}{T}\right)(4)
\end{gathered}
$$

Dalam aplikasinya, tekanan dibagi menjadi beberapa yaitu tekanan absolut ( $\mathrm{P}_{\mathrm{abs}}$ ), tekanan total $\left(\mathrm{P}_{\mathrm{t}}\right)$, tekanan parsial $\left(\mathrm{P}_{\mathrm{i}}\right)$, tekanan saturasi uap $\left(\mathrm{P}_{\mathrm{s}}\right)$, tekanan uap $\left(\mathrm{P}_{\mathrm{d}}\right)$, tekanan standar $\left(\mathrm{P}_{\mathrm{n}}\right)$ dan tekanan ultimate (Pend). Tekanan total merupakan jumlah dari tekanan parsial untuk semua gas dan uap didalam ruang tersebut. Tekanan parsial dari gas atau uap tertentu merupakan tekanan jika pada ruang tersebut hanya tersisa gas tersebut. Tekanan saturasi uap disebut juga tekanan dari uap saturasi yang merupakan fungsi dari temperature untuk masing masing zat. Tekanan uap merupakan tekanan parsial dari uap dimana dapat menjadi cair pada temperature nitrogen cair. Tekanan standar merupakan tekanan yang ditetapkan DIN 1343 sebesar 1013,25 mbar. Sedangkan tekanan ultimate merupakan tekanan

\section{METODE PENELITIAN}

Penelitian ini dilaksanakan pada Maret 2019 sampai dengan September 2019 di Laboratorium Teknik Mesin, Jurusan Teknik Mesin, Fakultas Mesin, Universitas Katolik Widya Karya Malang. Tahapan penelitian secara keseluruhan yang akan dilakukan ditunjukkan dalam blok diagram berikut:

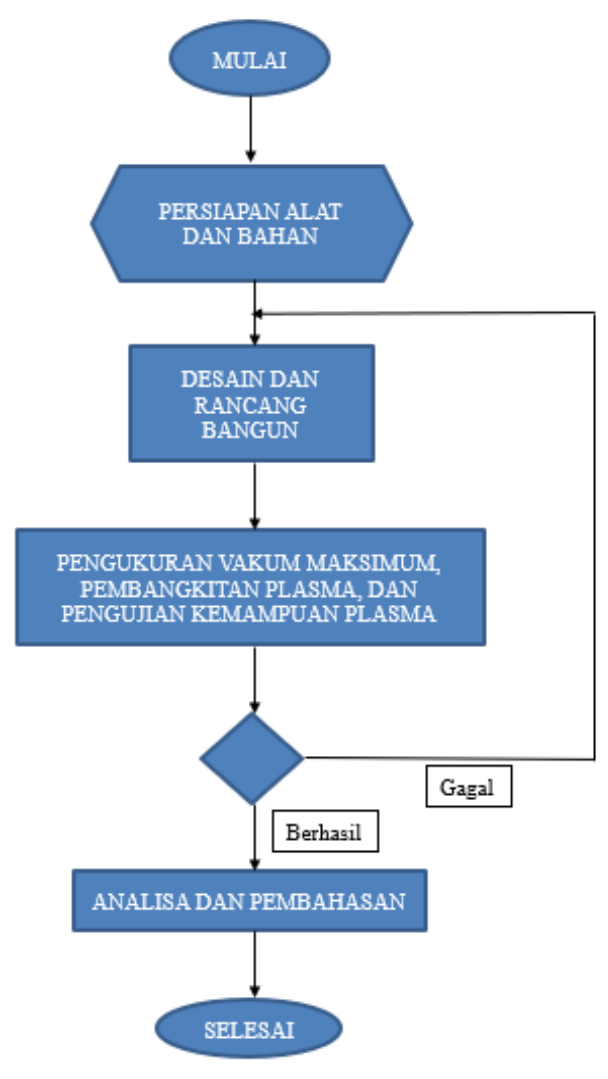

\section{HASIL DAN PEMBAHASAN}

Penelitian ini merupakan analisa atas hasil penelitian sebelumnya mengenai rancang bangun reaktor plasma. Wujud serta 
Jurnal PRAXIS | Vol. 2 | No. 2 | Maret 2020

gambar dari reaktor tersebut disajikan dalam gambar 2.

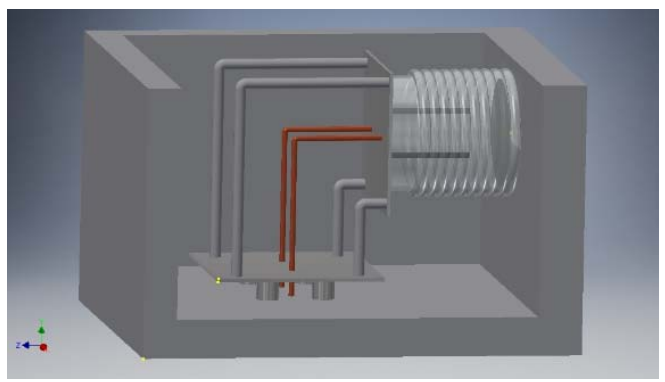

(a)

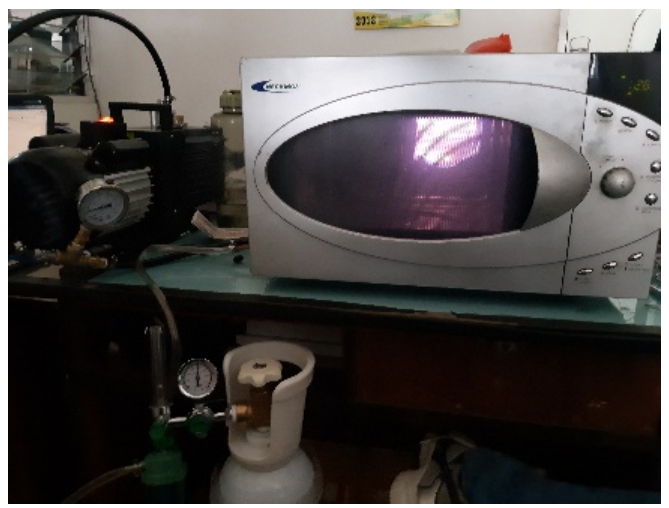

(b)

Gambar 2.

Reaktor Plasma dengan Pembangkitan Menggunakan Gelombang Mikro 2,45GHz.

(a) Gambar desain (b) Hasil implementasi desain (P \& Mbulu, 2018)

Pada proses vakum reaktor, level maksimum vakum yang dapat dicapai menggunakan pompa Rotary Vane Vacuum Pump 2XZ-4 adalah $2 \mathrm{cmHg}$ atau 0,026 bar atau 26.000 Pa. Pada pembangkitan plasma ini digunakan gas oksigen $80 \%$ sebagai gas plasma. Oksigen memiliki diameter molekul oksigen adalah $1,2 \times 10^{-10} \mathrm{~m}$ (Bransden \& Joachain, 1983). Tekanan awal reaktor berada pada tekanan atmosfer sebesar 100.000 Pa turun hingga 26.000 bar pada 10 detik proses vakum. Berangkat dari persamaan (1) dapat ditentukan kecepatan pompa. Nilai daya hisap pompa (Q) didapatkan dari perhitungan menggunakan persamaan (4):

$Q=\frac{d}{d t}(P V)$

Hasil dari perhitungan tersebut didapatkan besar daya hisap pompa (Q) sebesar 3,164 $\mathrm{Pa} \mathrm{m}^{3} / \mathrm{s}$. Besar daya hisap tersebut membuat proses vakum reaktor menjadi cenderung singkat untuk mencapai vakum maksimum yang dapat dicapai. Lebih dari 10 detik tersebut, level vakum reaktor tidak akan dapat turun lagi. Rendahnya level vakum memberikan keadaan di mana jumlah partikel gas di dalam reaktor menurun. Nilai mean free path partikel, yang merupakan jarak bebas antar partikel, dapat dihitung dengan menggunakan persamaan (2) dan didapatkan nilainya adalah $4,327 \times 10^{-6} \mathrm{~m}$. Artinya, jarak antar partikel di dalam reaktor lebih jauh jika dibandingkan pada tekanan atmosferik yaitu $1,11 \times 10^{-6} \mathrm{~m}$ pada temperatur sama. Namun, dampak lainnya adalah partikel dapat bergerak bebas sehingga berakibat pada tingginya momentum partikel tersebut diakibatkan ruang gerak bebas dan meningkatkan kecepatan partikel tersebut. 
Jurnal PRAXIS | Vol. 2 | No. 2 | Maret 2020

Pada kasus aktifasi reaktor ini, terjadi limit pada proses aktifasi plasma. Reaktor kaca tersebut hanya dapat bertahan selama 4 menit, lebih dari durasi tersebut reaktor pecah. Pecahnya reaktor diakibatkan kaca reaktor tidak dapat menahan tekanan dan panas dari plasma tersebut. Gelombang mikro yang dipancarkan magnetron memiliki frekuensi 2,45 GHz dan dengan menggunakan persamaan Planck:

$$
\mathrm{E}=\mathrm{h} . \mathrm{f}
$$

bisa didapatkan besar energi pada satu partikel adalah $1,623 \times 10^{-24}$ J. Jumlah partikel yang ada di dalam reaktor dapat diprediksikan menggunakan hukum Gas Ideal:

$$
\mathrm{P} . \mathrm{V}=\mathrm{n} \cdot \mathrm{R} \cdot \mathrm{T}
$$

Tekanan, volume serta temperatur digunakan data pengamatan untuk mendapatkan besar mol di dalam reaktor. Properti mekanik dari kaca untuk compressive strength adalah $1000 \mathrm{MPa}$ (Lehman, 2014), namun terdapat penekanan ke dalam akibat kondisi vakum reaktor dari 101.325 Pa turun hingga $25 \mathrm{kPa}$. Selain itu, mendapatkan tumbukan dari partikel partikel di dalam reaktor sehingga total kaca mendapatkan $1,858 \times 10^{17} \mathrm{kPa}$. Besarnya tekanan oleh partikel di dalam reaktor melebihi kemampuan dari reaktor kaca, sehingga reaktor pecah.

\section{SIMPULAN}

Reaktor plasma yang dibangkitkan menggunakan gelombang mikro 2,45 GHz ini masih memiliki potensi untuk ditingkatkan lagi. Dari kemampuan vakum pompa dan level vakum maksimum yang dapat dicapai masih berada di level rough vacuum. Pada keadaan tersebut terdapat $33,212 \times 10^{17}$ partikel yang memberikan tekanan kepada reaktor sebesar $1,858 \times 10^{17}$ $\mathrm{kPa}$ atau $1,858 \times 10^{14}$ Mpa yang mengakibatkan reaktor pecah dikarenakan compressive strength dari kaca hanya dapat menahan hingga $1000 \mathrm{MPa}$.

\section{DAFTAR PUSTAKA}

Bellan, P. M. (2006) Fundamentals of Plasma Physics. New York: Cambridge University Press.

Conrads, H. and Schmidt, M. (2000) 'Plasma generation and plasma sources', Plasma Sources Science and Technology, 9(4), pp. 441-454. doi: 10.1088/0963-0252/9/4/301. 
Grigoryev, Y. N. and Gorobchuk, A. G. (2014) 'Numerical Modeling of Plasma-Chemical Etching Technology in CF4/H2 Gas Mixture', International Conference on the Methods of Aerophysical Research, 29(2), pp. 1-6.

Nehra, V., Kumar, A. and Dwivedi, H. K. (2008) 'Atmospheric Non-Thermal Plasma Sources', International Journal of Engineering, 2(1), pp. 5368.

O'Hanlon, J. F. (2003) A User's Guide to Vacuum Technology. 3rd edn. New Jersey: John Wiley \& Sons, Inc.

P, A. P. J. and Mbulu, B. C. P. (2018) 'Rancang Bangun Reaktor Plasma dan Studi Pengaruh Laju Alir Gas Oksigen Terhadap Laju Ashing Karbon pada Baja K110’, Natural B, 04.

Umrath, W. (1998) Fundamentals of vacuum technology. Book on Demand. 